\title{
Synthesis of Some Tailor-Made Poly(benzo-19-crown-6)s via Cyclopolymerization of Divinyl Ether with Hydrogen Iodide/Iodine Initiator
}

\author{
Toyoji KaKUCHI, Osamu KobaYAShI, Daigo NaKayA, \\ and Kazuaki YoKOTA \\ Department of Chemical Process Engineering, Faculty of Engineering, \\ Hokkaido University, Kita-ku, Sapporo 060, Japan
}

(Received February 22, 1989)

\begin{abstract}
Cationic cyclopolymerization of 1,2-bis[2-(2-vinyloxyethoxy)ethoxy]benzene (1) via a long-lived intermediate was achieved by the hydrogen iodide/iodine $\left(\mathrm{HI} / \mathrm{I}_{2}\right)$ initiating system to give poly(benzo-19-crown-6). The molecular weight distribution of the polymer obtained was relatively narrow as $M_{w} / M_{n} \leq 1.4$ in dichloromethane at -60 and $-72^{\circ} \mathrm{C}$. The degree of polymerization agreed with the predicted value for the $[1] /[\mathrm{HI}]$ ratio below 10 . The poly(crown ether) with a reactive end group could be prepared through the polymerization of 1 initiated with $\mathrm{I}_{2}$ and the hydroiodinated adduct of a monovinyl ether; i.e., a dimethylmethoxysilyl-capped polymer from dimethylmethoxy[4-(2-vinyloxyethoxy)phenyl]silane and a macromonomer from 2-vinyloxyethyl methacrylate.
\end{abstract}

KEY WORDS Cyclopolymerization / Divinyl Ether / Living Polymerization / Hydrogen Iodide / Iodine / Poly(benzo-19-crown-6) / End-Functionalized Polymer / Macromonomer /

We established that the cyclopolymerization of bifunctional monomers is an effective method for preparing polymers with various cyclic repeating units. ${ }^{1}$ Divinyl ethers are polymerized with tin(VI) chloride and boron trifluoride etherate as typical cationic initiator to give gel-free polymers whose constitutional repeating units are essentially crown ethers $^{2}$ including chiral ones. ${ }^{3}$ Modification of this polymerization may lead to poly(crown ether) with a reactive end group, which can be used for producing graft copolymers with well-characterized crown ether branches. The aim of this article, then, is the synthesis of such polymers via cyclopolymerization.

Higashimura et al. found that hydrogen iodide, combined with iodide ( $\mathrm{HI} / \mathrm{I}_{2}$ initiator), induces living polymerization of alkyl vinyl ethers to yield monodisperse polymers. The living cationic polymerization can be utilized to synthesize block copolymers, macromonomers, telechelic polymers, and functional polymers. ${ }^{4}$

For the present purpose, the $\mathrm{HI} / \mathrm{I}_{2}$ initiating system is therefore appropriate, in that it may lead to living cyclopolymerization of divinyl ethers. There has been, however, no attempt to produce a living system in the cyclopolymerization. This communication describes the cyclopolymerization of 1,2-bis[2-(2-vinyloxyethoxy)ethoxy]benzene (1) with $\mathrm{HI} / \mathrm{I}_{2}$ and the syntheses of an end-functionalized polymer (4a) and a macromonomer (4b) with poly(crown ether) units under living polymerization conditions.

\section{EXPERIMENTAL}

\section{Procedures}

Polymerization was carried out by a proce- 

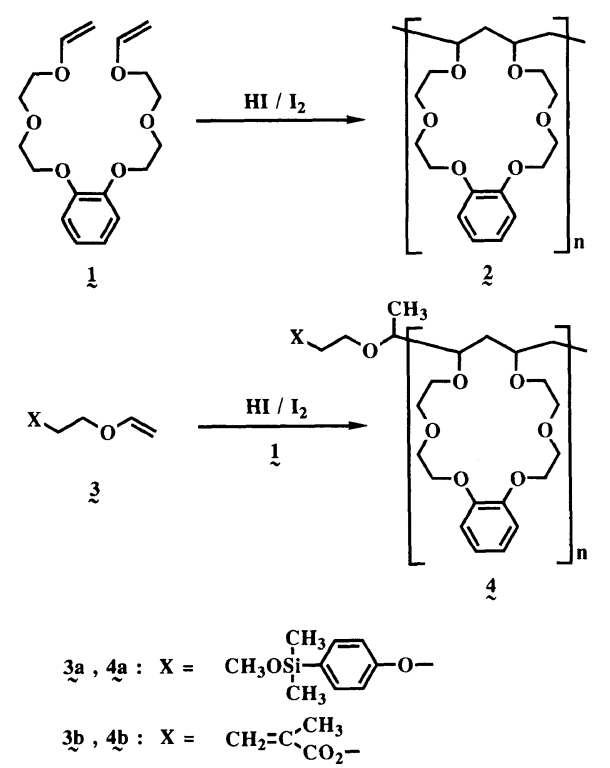

Scheme 1.

dure similar to that reported by Higashimura et al. ${ }^{5}$ 1,2-Bis[2-(2-vinyloxyethoxy)ethoxy]benzene (1) in toluene or dichloromethane was treated with a solution of hydrogen iodide in $n$ hexane and then with a solution of iodine in $n$ hexane. The polymerization was initiated by the hydrogen iodide-vinyl ether adduct thus obtained, in conjunction with iodine. For the synthesis of a poly(crown ether) with a reactive end group, hydrogen iodide was treated with an equimolar amount of dimethylmethoxy[4-(2-vinyloxyethoxy)phenyl]silane (3a) or 2-vinyloxyethyl methacrylate (3b) to form the adduct, and the polymerization was initiated by adding a prechilled solution of 1 to a mixture of the adduct and iodine in the prescribed solvent. The reaction was terminated with ammoniacal methanol. The purification of the product was carried out by extraction with toluene and by washing with dilute sodium thiosulfate solution. Evaporating the extract in a high vacuum afforded a viscous material. Conversions of the monomer were determined by ${ }^{1} \mathrm{H}$ NMR spectra of the resulting material. The molecular weight distribution (MWD) of the resulting polymers was measured by gel permeation chromatography
(GPC) in tetrahydrofuran on a WATERS M45 high-performance liquid chromatograph equipped with three polystyrene gel columns (Shodex A-802, A-803, and A-805).

\section{Materials}

Synthesis of 1,2-bis[2-(2-vinyloxyethoxy)ethoxy]benzene (1) was reported in a previous paper. ${ }^{2} 2$-Vinyloxyethyl methacrylate (3b) was prepared from 2-chloroethyl vinyl ether and sodium methacrylate by a phase-transfer reaction in the presence of a small quantity of tetrabutylammonium iodide. ${ }^{6}$ Hydrogen iodide was obtained from a $57 \%$ aqueous solution by dehydration with phosphorous pentaoxide and stored as an $n$-hexane solution. Iodine was sublimed over potassium iodide under reduced pressure and stored as an $n$ hexane solution.

1-Bromo-4-(2-vinyloxyethoxy)benzene: To a solution of $p$-bromobenzene $(27 \mathrm{~g}, 0.16 \mathrm{~mol})$ and sodium hydroxide $(9.6 \mathrm{~g}, 0.24 \mathrm{~mol})$ in dimethyl sulfoxide $(25 \mathrm{ml})$ was added 2-chloroethyl vinyl ether $(20 \mathrm{~g}, 0.19 \mathrm{~mol})$, and the mixture was stirred at $90^{\circ} \mathrm{C}$ for $6 \mathrm{~h}$, cooled, diluted with water, and extracted with dichloromethane. The extracts were washed with dilute sodium hydroxide solution, then dried and evaporated. The residue was recrystallized from $n$-hexane, giving a white crystal with $\mathrm{mp}$ $62{ }^{\circ} \mathrm{C}$ in $82.0 \%$ yield $(30 \mathrm{~g}) .{ }^{1} \mathrm{H}$ NMR $\left(\mathrm{CDCl}_{3}\right)$ : $\delta=7.37(\mathrm{~d}, 2 \mathrm{H}), 6.79(\mathrm{~d}, 2 \mathrm{H}), 6.51 \quad(\mathrm{dd}$, $\left.1 \mathrm{H}, J_{\text {cis }}=6.8 \mathrm{~Hz}, J_{\text {trans }}=14.3 \mathrm{~Hz}\right), 4.33-3.97$ $\mathrm{ppm}(\mathrm{m}, 6 \mathrm{H})$.

Dimethylmethoxy[4-(2-vinyloxyethoxy)phenyl]silane (3a): Dichlorodimethylsilane $(29 \mathrm{ml}, 0.24 \mathrm{~mol})$ was stirred with magnesium turning $(3.8 \mathrm{~g}, 0.17 \mathrm{~mol})$ and 1-bromo-4-(2vinyloxyethoxy)benzene $(29.2 \mathrm{~g}, 0.12 \mathrm{~mol})$ in tetrahydrofuran $(60 \mathrm{ml})$ with exclusion of air and moisture. The reaction was started by adding small quantities of ethyl bromide and iodine. After stirring at $25^{\circ} \mathrm{C}$ for about $1 \mathrm{~h}$, the solution was diluted with dry pyridine $(120 \mathrm{ml})$ and then treated with a mixture of dry methanol $(40 \mathrm{ml})$ and dry pyridine $(30 \mathrm{ml})$. Finally 
Table I. Polymerization of 1,2-bis[2-(2-vinyloxyethoxy)ethoxy]benzene (1) by $\mathrm{HI} / \mathrm{I}_{2}{ }^{\mathrm{a}}$

\begin{tabular}{|c|c|c|c|c|c|c|c|c|}
\hline \multirow{2}{*}{ Solvent } & \multirow{2}{*}[\mathbf{1}]{$/[\mathrm{HI}]$} & \multirow{2}{*}{$\frac{\left[\mathrm{I}_{2}\right]}{\mathrm{mmol} / 1}$} & \multirow{2}{*}{$\frac{\text { Temp. }}{{ }^{\circ} \mathrm{C}}$} & \multirow{2}{*}{$\frac{\text { Time }}{\mathrm{h}}$} & \multirow{2}{*}{$\frac{\text { Conv. }}{\%}$} & \multicolumn{2}{|c|}{$P_{n}^{\mathrm{b}}$} & \multirow{2}{*}{$M_{\mathrm{x}} / M_{n}^{\mathrm{b}}$} \\
\hline & & & & & & Calc. & Found & \\
\hline \multirow[t]{7}{*}{$\mathrm{CH}_{2} \mathrm{Cl}_{2}$} & 10 & 0.1 & -20 & 1 & 100 & 10 & 7.7 & 1.61 \\
\hline & 10 & 0.1 & -40 & 1 & 100 & 10 & 10.2 & 1.58 \\
\hline & 10 & 0.5 & -60 & 1 & $100^{\mathrm{c}}$ & 10 & 9.6 & 1.42 \\
\hline & 10 & 5.0 & -72 & 1 & $100^{c}$ & 10 & 10.2 & 1.35 \\
\hline & 20 & 3.0 & -72 & 2 & 100 & 20 & 12.6 & 1.45 \\
\hline & 40 & 2.0 & -72 & 6 & 100 & 40 & 19.9 & 1.53 \\
\hline & 80 & 1.0 & -72 & 8 & 60 & 48 & 10.9 & 1.50 \\
\hline \multirow[t]{7}{*}{$\mathrm{C}_{6} \mathrm{H}_{5} \mathrm{CH}_{3}$} & 10 & 0.1 & -20 & 1 & 100 & 10 & 11.6 & 1.90 \\
\hline & 10 & 0.1 & -40 & 1 & 73 & 7.3 & 12.1 & 1.90 \\
\hline & 10 & 0.5 & -60 & 1 & 72 & 7.2 & 10.5 & 1.62 \\
\hline & 10 & 5.0 & -72 & 1 & 87 & 8.7 & 14.7 & 1.64 \\
\hline & 20 & 3.0 & -53 & 2 & 100 & 20 & 17.4 & 1.71 \\
\hline & 40 & 2.0 & -53 & 6 & 89 & 35.6 & 20.6 & 1.63 \\
\hline & 80 & 1.0 & -53 & 24 & 100 & 80 & 21.0 & 2.11 \\
\hline
\end{tabular}

${ }^{a}[1]=0.1 \mathrm{moll}^{-1}$.

b Measured by GPC.

c Polymerization was terminated with diethylamine.

the mixture was stirred for a further $12 \mathrm{~h}$ and then diluted with ether. The ether layer was separated and freed from the solvent. The residue was distilled under vacuum to give a colorless oil with bp $114-116^{\circ} \mathrm{C} / 7 \times 10^{-4}$ $\mathrm{mmHg}$ in $29 \%$ yield $(9.5 \mathrm{~g}) .{ }^{1} \mathrm{H}$ NMR $\left(\mathrm{CDCl}_{3}\right)$ : $\delta=7.50(\mathrm{~d}, 2 \mathrm{H}), 6.95(\mathrm{~d}, 2 \mathrm{H}), 6.43(\mathrm{dd}, 1 \mathrm{H}$, $\left.J_{\text {cis }}=6.8 \mathrm{~Hz}, J_{\text {trans }}=14.0 \mathrm{~Hz}\right), 4.33-3.97(\mathrm{~m}$, $6 \mathrm{H}), 3.41(\mathrm{~s}, 3 \mathrm{H}), 0.35 \mathrm{ppm}(\mathrm{s}, 6 \mathrm{H})$.

$\mathrm{C}_{13} \mathrm{H}_{18} \mathrm{O}_{3} \mathrm{Si}$ (250.35). Found: C, 62.12\%; $\mathrm{H}, 8.23 \%$. Calcd: C, $61.86 \%$; H, $7.93 \%$.

\section{RESULTS AND DISCUSSION}

\section{Cyclopolymerization with $\mathrm{HI} / \mathrm{I}_{2} \quad$ Initiating System}

The polymerization results for monomer 1 are listed in Table I. The polymerizations proceed homogeneously up to high conversion, except for the polymerizations at $-53^{\circ} \mathrm{C}$ or below in toluene. The reaction system turns yellow or reddish-yellow, which disappears upon termination with ammoniacal methanol. All the products are yellowish, somewhat sticky semi-solids soluble in benzene, chlo-

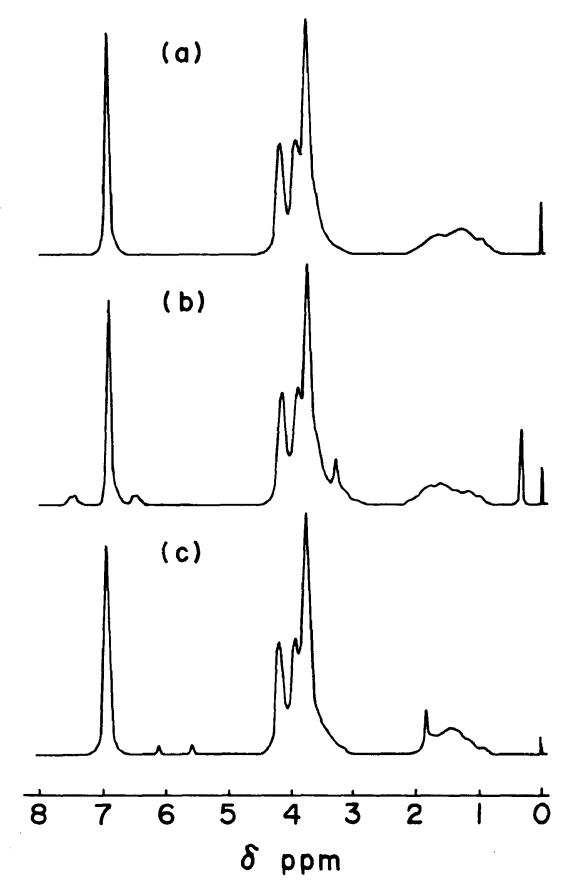

Figure 1. The ${ }^{1} \mathrm{H}$ NMR spectra of the tailor-made poly(benzo-19-crown-6)s: (a) homopolymer 2 obtained in dichloromethane at $-72^{\circ} \mathrm{C},[1] /[\mathrm{HI}]=10$; (b) endreactive polymer $\mathbf{4 a}$ obtained in dichloromethane at $-76^{\circ} \mathrm{C},[1] /[3 \mathrm{a}]=5$; (c) macromonomer $4 \mathrm{~b}$ obtained in dichloromethane/toluene (volume ratio, $1: 3$ ) at $-20^{\circ} \mathrm{C}$, $[\mathbf{1}] /[3 \mathbf{b}]=5$. 
roform, and tetrahydrofuran. Since the ${ }^{1} \mathrm{H}$ NMR spectra of the polymers indicated the absence of the vinyloxy group (Figure 1(a)), the polymers consist essentially of cyclic constitutional repeating units, namely benzo-19crown- 6 , in analogy with the polymerizations of 1 with conventional cationic catalysts. ${ }^{2}$

In the polymerizations in dichloromethane, the monomer was completely consumed to give polymers with degrees of polymerization $\left(P_{n}\right)$ of 10.2 at $-40^{\circ} \mathrm{C}, 9.6$ at $-60^{\circ} \mathrm{C}$, and 10.2 at $-72^{\circ} \mathrm{C}$; these values correspond to the [1]/ [HI] molar ratio of 10 . The $M_{w} / M_{n}$ ratio is somewhat broader than those for the living polymerization of alkyl vinyl ethers, which do not exceed 1.1. ${ }^{4}$ The molecular weight distribution (MWD) was narrowed with lowering temperature, but the ratio was still 1.35 at $-72^{\circ} \mathrm{C}$. The polymerizations at $-60^{\circ} \mathrm{C}$ and $-72^{\circ} \mathrm{C}$ were terminated with diethylaminecontaining methanol. The $P_{n}$, calculated from the relative intensity of the aminoethyl and phenyl protons in the ${ }^{1} \mathrm{H}$ NMR spectra of the polymers, was 11.3 at $-60^{\circ} \mathrm{C}$, and 11.8 at $-72^{\circ} \mathrm{C}$, which is in good agreement with those determined by GPC relative to polystyrene. Thus the cyclopolymerization of 1 with $\mathrm{HI} / \mathrm{I}_{2}$ proceeds via a long-lived intermediate. The $P_{n}$, however, deviated from the predicted value at the $[1] /[\mathrm{HI}]$ ratio of 20 or above, which means the occurrence of a chain transfer reaction.

For the polymers obtained in toluene, which is a better solvent for living cationic polymerization than dichloromethane, ${ }^{4}$ the $P_{n}$ was larger than the value calculated from the amount of the consumed monomer at the $[1] /[\mathrm{HI}]$ ratio of 10 , but above this ratio, $P_{n}$ was smaller than the calculated values. The MWDs of the polymers formed are illustrated in Figure 2. The GPC traces showed clearly bimodal distributions for the polymers obtained in toluene; this differs from unimodal distributions for the polymers in dichloromethane. The behavior of the polymerization in toluene is interpreted by the poor solubility of the polymer in the reaction medium and by the formation of the

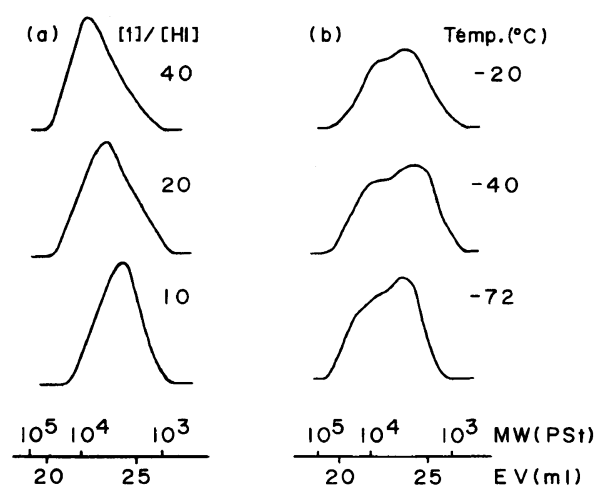

Figure 2. MWD of poly(benzo-19-crown-6) obtained with the $\mathrm{HI} / \mathrm{I}_{2}$ initiating system in (a) dichloromethane at $-72^{\circ} \mathrm{C}$; in (b) toluene at $[1] /[\mathrm{HI}]=10$.

dihydroiodinated compound of $\mathbf{1}$ that induces a bifunctional initiation.

The $\mathrm{HI} / \mathrm{I}_{2}$ initiating system led to a livinglike cyclopolymerization for monomer $\mathbf{1}$ in dichloromethane at the $[1] /[\mathrm{HI}]$ ratio of 10 .

\section{Preparation of Poly(crown ether) with a \\ Reactive End Group through Cyclopolymeri- zation}

Some results of applying the living-like character to the syntheses of a terminally monofunctional polymer and macromonomer are listed in Table II. All the reactions are homogeneous, and the viscous polymers obtained are soluble in benzene, chloroform, and tetrahydrofuran. In the polymerizations using the initiator derived from dimethylmethoxy[4-(2vinyloxyethoxy)phenyl]silane (3a) and hydrogen iodide in dichloromethane, the MWDs are rather broad with the $M_{w} / M_{n}$ ratio from 1.31 to $1.62 . P_{n}$ is 4.7 at the $[1] /[3]$ ratio of 5 , but deviates greatly from the predicated value at the ratio above 5; this result is similar to that of the homopolymerization of $\mathbf{1}$, a situation caused by dichloromethane being an unsatisfactory solvent for the living polymerization. ${ }^{4}$ Therefore, a mixed solvent of toluene and dichloromethane is used for facilitating the smooth addition of hydrogen iodide to 2vinyloxyethyl methacrylate (3b) and keeping the polymerization homogeneous. The values 
Table II. Polymerization of 1,2-bis[2-(2-vinyloxyethoxy)ethoxy]benzene (1) initiated by dimethylmethoxy[4-(2-vinyloxyethoxy)phenyl]silane (3a) and 2-vinyloxyethyl methacrylate (3b) with $\mathrm{HI} / \mathrm{I}_{2}{ }^{a}$

\begin{tabular}{|c|c|c|c|c|c|c|}
\hline Monovinyl ether & {$[1] /[3]$} & Solvent ${ }^{\mathrm{b}}$ & $\frac{\text { Temp }}{{ }^{\circ}}$ & $\frac{\text { Time }}{\mathrm{h}}$ & $P_{n}{ }^{\mathrm{d}}$ & $M_{w} / M_{n}^{\mathrm{d}}$ \\
\hline \multirow[t]{3}{*}{$3 a$} & 5 & D & -76 & 2 & $4.7(5.3)$ & 1.62 \\
\hline & 8.8 & $\mathrm{D}$ & -76 & 2 & 4.6 & 1.31 \\
\hline & 25.5 & $\mathrm{D}$ & -76 & 2 & 10.4 & 1.48 \\
\hline \multirow[t]{4}{*}{$\mathbf{3 b}$} & 5 & $\mathrm{D} / \mathrm{T}(1: 1)^{\mathrm{c}}$ & -40 & 1 & $4.5(4.5)$ & 1.52 \\
\hline & 10 & $\mathrm{D} / \mathrm{T}(1: 1)$ & -40 & 1 & 7.6 & 1.45 \\
\hline & 5 & $\mathrm{D} / \mathrm{T}(1: 3)$ & -20 & 1 & $4.5(4.9)$ & 1.53 \\
\hline & 10 & $\mathrm{D} / \mathrm{T}(1: 3)$ & -20 & 1 & 10.5 & 1.45 \\
\hline
\end{tabular}

a $[1]=0.1 \mathrm{~mol}^{-1} ;[3]=[\mathrm{HI}] ;\left[\mathrm{I}_{2}\right]=0.1 \mathrm{mmol}^{-1}$; yield, $100 \%$.

b $\mathrm{D}=$ dichloromethane; $\mathrm{T}=$ toluene.

c Volume ratio.

${ }^{d}$ Measured by GPC. The values in parenthesis were determined by ${ }^{1} \mathrm{H}$ NMR spectra.

of $P_{n}$ are in fair agreement with those predicted from the $[1] /[3]$ molar ratio, especially at the toluene/dichloromethane volume ratio of 3, though the MWDs are somewhat broad.

The ${ }^{1} \mathrm{H}$ NMR spectra of polymers $4 \mathbf{a}$ and $\mathbf{4 b}$ showed characteristic resonances at $\delta 3.41$ and $0.35 \mathrm{ppm}$ due to the methyl and methoxy protons, respectively, for $\mathbf{4 a}$, and at $\delta 5.5,6.1$, and $1.9 \mathrm{ppm}$ due to the olefinic and methyl protons, respectively, for $\mathbf{4 b}$, in addition to the resonances for the homopolymer $\mathbf{2}$, as shown in Figure 1. The spectroscopic data thus confirm the presence of the dimethylmethoxysilyl and the methacrylate groups in the polymers 4a and $4 \mathbf{b}$, respectively. The $P_{n}$, determined by GPC, at the [1]/[3] ratio of 5, was in good agreement with those calculated from the relative intensity of the silylmethyl and phenyl protons for $\mathbf{4 a}$, and of the vinyl and phenyl protons for $\mathbf{4 b}$. End-reactive polymer $4 \mathbf{a}$ effectively reacted with activated silica gel in toluene under reflux. Macromonomer 4b could be copolymerized with methyl methacrylate in toluene with AIBN at $60^{\circ} \mathrm{C}$ to yield poly(methyl methacrylate) grafted with poly(benzo-19-crown-6).

This indicates that the $\mathrm{HI} / \mathrm{I}_{2}$ initiating system is extremely useful for preparing tailor- made poly(crown ether)s through cyclopolymerization.

Acknowledgement. This work was supported by the General Sekiyu Research \& Development Encouragement \& Assistance Foundation which we acknowledge gratefully.

\section{REFERENCES}

1. K. Yokota, H. Hashimoto, T. Kakuchi, and Y. Takada, Makromol. Chem., Rapid Commun., 5, 115 (1984); K. Yokota, H. Hashimoto, T. Kakuchi, and Y. Takada, ibid., 5, 767 (1984); K. Yokota, T. Kakuchi, Y. Taniguchi, and Y. Takada, ibid., 6, 155 (1985); K. Yokota, T. Kakuchi, M. Yamanaka, and Y. Takada, ibid., 7, 633 (1986).

2. K. Yokota, M. Matsumura, K. Yamaguchi, and Y. Takada, Makromol. Chem., Rapid Commun., 4, 721 (1983).

3. T. Kakuchi and K. Yokota, Makromol. Chem., Rapid Commun., 6, 551 (1985); T. Kakuchi, H. Sasaki, and K. Yokota, Makromol. Chem., 189, 1279 (1988); T. Kakuchi, T. Takaoka, and K. Yokota, ibid., 189, 2007 (1988).

4. T. Higashimura and M. Sawamoto, "Comprehensive Polymer Science," Vol. 3, G. Allen and J. Bevington, ed., Pergamon Press, Oxford, 1989, p 684.

5. M. Miyamoto, M. Sawamoto and T. Higashimura, Macromolecules, 17, 265 (1984).

6. K. Kato, T. Ichijo, K. Ishii, and M. Hasegawa, $J$. Polym. Sci., A-1, 9, 2109 (1971). 